\title{
Three-phase hybrid transformer using matrix-chopper as an interface between two AC voltage sources
}

\author{
J. Kaniewski, Z. Fedyczak, P. SzczeŚniak \\ Institute of Electrical Engineering, University of Zielona Góra \\ Zielona Góra, Poland \\ e-mail:\{J.Kaniewski/Z.Fedyczak/P.Szczesniak\}@iee.uz.zgora.pl
}

(Received: 26.11.2013, revised: 12.02.2014)

\begin{abstract}
This paper deals with a three-phase power system with hybrid transformer (HT) installed between two AC sources. The main aim of this paper is analyze the basic properties of HT with active load and ability to bidirectional energy flow. The HT contains two main units - a conventional transformer with electromagnetic coupling and PWM AC line chopper connected with secondary windings with electric coupling. The HT is located between the distribution system and a Local Balancing Area (LBA) with low power local energy sources. After describing the HT circuit and three-phase, twosources power system, the mathematical and circuit models of the AC source with HT are presented. These models are verified by means of the simulation and experimental test results obtained for a three-phase HT of about $3 \mathrm{kVA}$ rated power.
\end{abstract}

Key words: hybrid transformer, power system, matrix chopper

\section{Introduction}

The parameters of electric energy, its quality, are very important especially from the viewpoint of the end-user. The parameters of electric energy are well known and described in [1]. Classification of $\mathrm{AC}$ voltage variation is shown in Figure 1. The voltage interruptions are divided into two types: short interruption (from $10 \mathrm{~ms}$ to 3 minutes) and long interruption (over 3 minutes) (Fig. 1).

An Expanded and centralized AC electrical system is exposed to many different faults. Moreover the energy is often transferred in the long distances (Fig. 2a). The causes and effects of distortion in AC electrical system are shown in Figure 2. In the case of dynamic variations in an $\mathrm{AC}$ electrical system, e.g. fast load changes, switching effects, atmospheric discharges, faults, on the consumer side, undesirable effects are generated, such as voltage dips $(87.2 \%$ of all distortion in the power grid), interruptions and swells (Fig. 2b) [2, 3].

In the case of the AC voltage supply changes, both downward and upward, there is a high risk of damage to devices, which are sensitive to voltage changes, for example: computers, transceiver devices, medical systems [4-6]. 


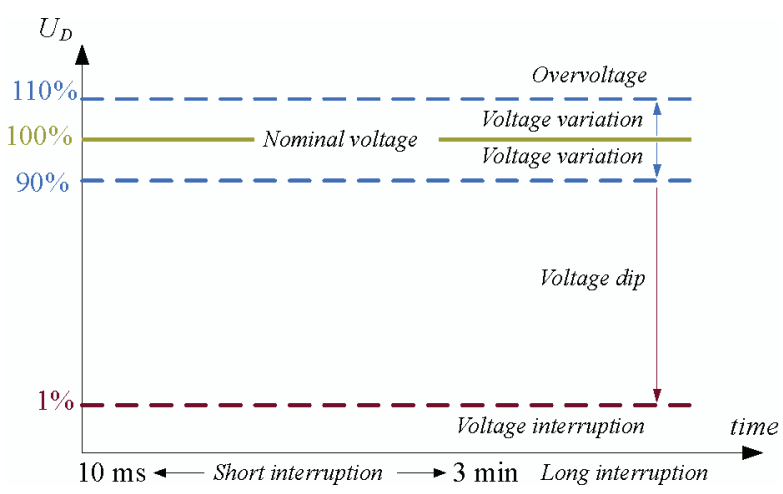

Fig. 1. Classification of voltage variation depending on size of chan ge, $U_{D}$ - declared supply voltage

a)

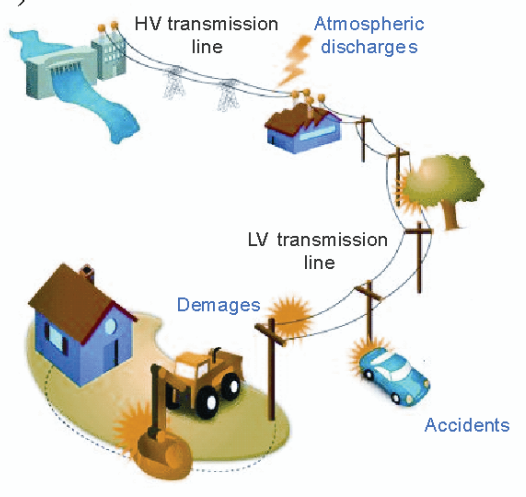

b)

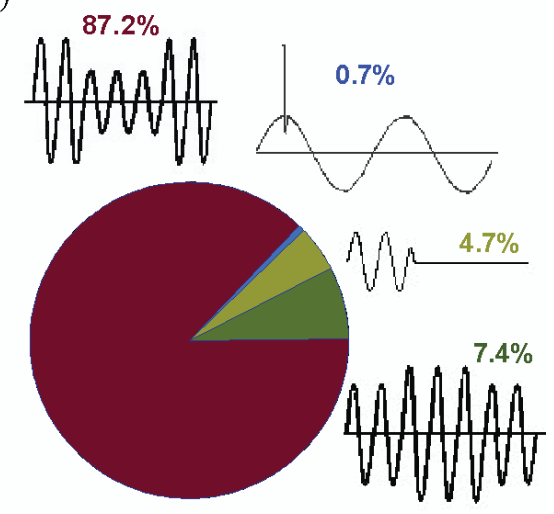

Fig. 2. Distortion in power grid - a) causes, b) effects

In the case of big plants and factories, voltage sags and swells may cause very large financial damage. The application of an AC-AC converter using Pulse Width Modulation (PWM) control strategy to build secondary supply sources (voltage sag and swell compensators and voltage regulators) mitigate unwanted detrimental effects in the supply [8-12]. Some types of $\mathrm{AC}$ voltage controller for compensation of deep and rapid voltage sags and overvoltages use the hybrid transformer (HT) described in [13-19]. A simplified schematic diagram of a HT connected to the AC power system is shown in Figure 3. In this case the HT unit is working with a passive load as an AC voltage controller.

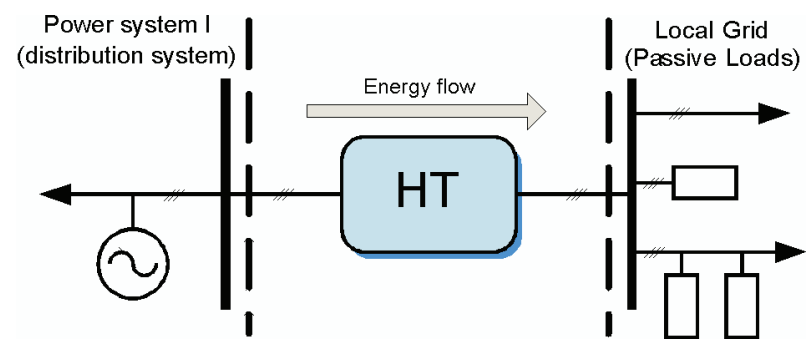

Fig. 3. Hybrid transformer installed in power system with passive load 
In the case of modern $\mathrm{AC}$ power systems (smart grids) there are possibilities to connect low power renewable energy sources (photo voltaic panels - PV, wind generators) to low voltage AC systems. The renewable energy sources are connected to the grid by power electronic interfaces $[8,9]$. Voltage fluctuations in low voltage AC power systems can be caused by turning on and turning off of renewable energy sources connected to the grid, being dependent on the condition of the source energy (wind, sun, water flow, etc.). Local AC systems (subsystems), such as residential houses, schools, academic campuses, etc., along with low power energy sources connected to a local AC subsystem is called a "Local Balancing Area" (LBA). In a LBA with low power local energy sources, during the operation of the subsystem there is a risk of change (fluctuation) in voltage amplitude in the LBA. This is caused by operational conditions (turn-on and turn-off) of energy sources connected to the LBA. In the case of a HT connected to a power system with a LBA (Fig. 4), the HT in fact is loaded by active load. For this reason it is necessary to obtain bidirectional power flow in the HT circuit.

Fig. 4. Hybrid transformer installed in modern power system with active load

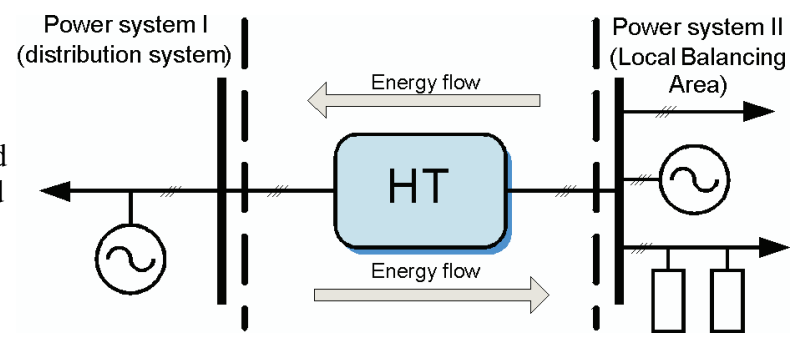

This paper presents the modelling and analysis of a three phase hybrid transformer using the matrix chopper described in [15] with active load (two-sided supply). The next chapter describes the topology and operation of the presented HT. Following this are chapters on the simulation and experimental test results and conclusions.

\section{Description of analysed circuit}

The schematic diagram of the considered HT with active load is shown in Figure 5. The circuit of the HT contains two main units. The first one is a three-phase conventional transformer (TR), with two secondary windings in each phase. The second one is a three-phase matrix chopper (MC). Primary windings are in Y-configuration. The main secondary windings $\left(a_{1}, a_{2}, a_{3}\right)$ of the TR are also $Y$-configured and, by an input filter $L_{F} C_{F}$, are connected with the MC. Secondary phase windings $\left(b_{1}, b_{2}, b_{3}\right)$ are connected in series with the output filter $L_{L} C_{L}$ of the MC. The voltages of the transformer secondary windings $a_{1}, a_{2}, a_{3}$ and $b_{1}, b_{2}, b_{3}$ are set with the ratios $p_{a}=4 / 3$ and $p_{b}=2 / 3$ respectively $[15,16]$. Output voltages of the HT $\left(u_{L 1}, u_{L 2}\right.$, $\left.u_{L 3}\right)$ are the sum of secondary voltages $\left(p_{b} u_{S 1}, p_{b} u_{S 2}, p_{b} u_{S 3}\right)$ and the phase output voltages of the MC. The output voltages of the HT $\left(u_{L 1}, u_{L 2}, u_{L 3}\right)$ are controlled by means of a control unit. The voltages $u_{01}, u_{02}, u_{03}$ are voltages of power system II (LBA) with active load (Fig. 5). 


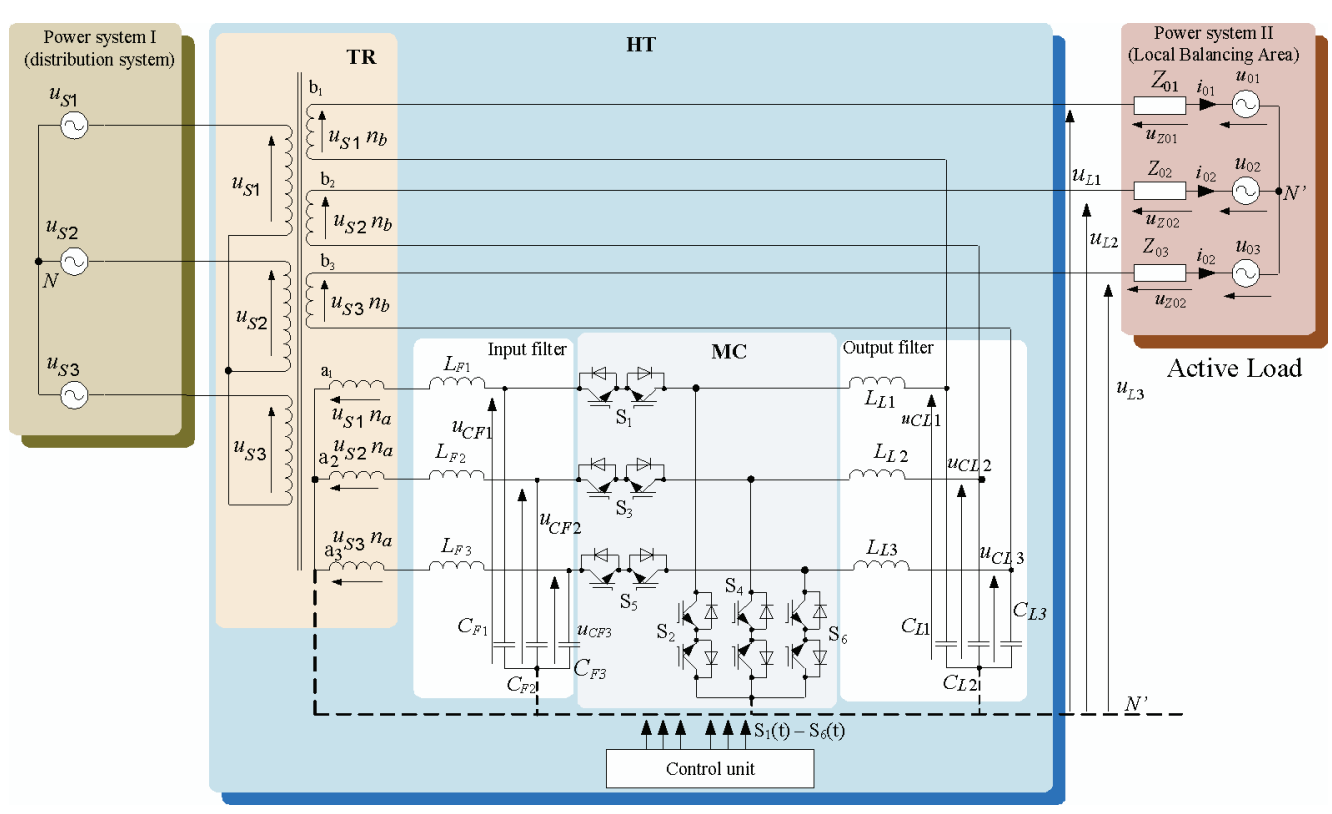

Fig. 5. Three-phase hybrid transformer using matrix chopper with active load

Exemplary idealized voltage time waveforms and voltage phasors, illustrating operation of presented HT with matrix chopper working as an AC voltage regulator are shown in Figure 6.

a)

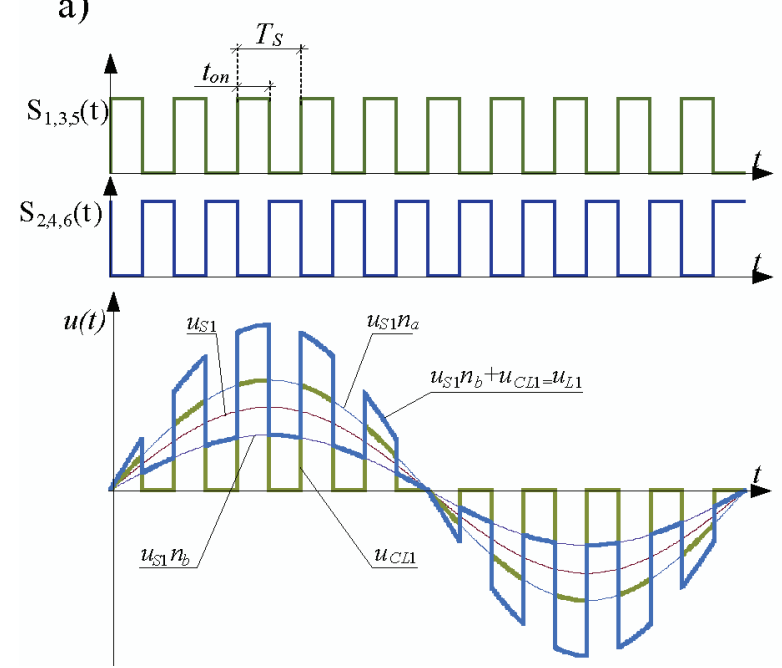

b)

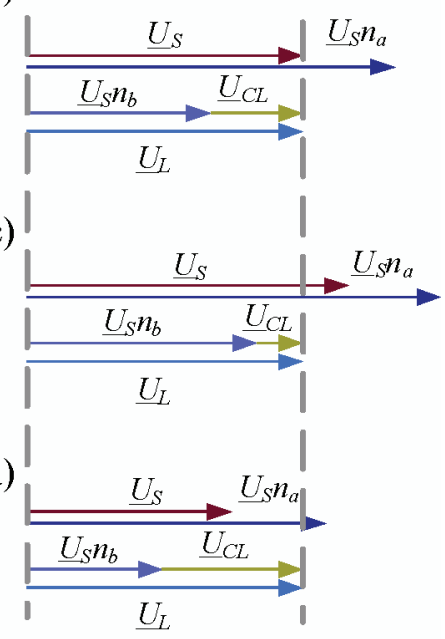

Fig. 6. Exemplary idealized voltages of HT: a) time waveforms at switching frequency $f_{S}=500 \mathrm{~Hz}$, b) phasors during nominal conditions, c) during source voltage swell, d) during source voltage sag 
The duty cycle of the control signal of $\mathrm{MC}$ switches $\left(\mathrm{S}_{1}-\mathrm{S}_{6}\right)$ is expressed as

$$
D=\frac{t_{o n}}{T_{S}},
$$

where $T_{S}$ - switching period, $t_{o n}$ - turn-on time of switches $\mathrm{S}_{1}, \mathrm{~S}_{3}, \mathrm{~S}_{5}$.

The output voltage of $\mathrm{MC}\left(u_{C L 1}, u_{C L 2}, u_{C L 3}\right)$ is linear depending on $D[15,16]$ and can by written as (2).

$$
U_{C L} \cong n_{a} U_{S} D .
$$

The output voltage of HT $\left(u_{L 1}, u_{L 2}, u_{L 3}\right)$ results from the addition of two voltages. The output voltage of $\mathrm{MC}\left(u_{C L 1}, u_{C L 2}, u_{C L 3}\right)$ and secondary voltage $\left(u_{S 1} n_{b}, u_{S 2} n_{b}, u_{S 3} n_{b}\right)$ is induced in secondary windings of TR $\left(b_{1}, b_{2}, b_{3}\right)$. Therefore load voltage of HT can by expressed as

$$
U_{L} \cong n_{a} U_{S} D+n_{b} U_{S} .
$$

According to (2), the idealized voltage transmittance of MC can be written as (4) $[15,16]$ and is shown in Figure 7.

$$
H_{U}^{M C} \cong \frac{U_{C L}}{n_{a} U_{S}}=\frac{n_{a} U_{S} D}{n_{a} U_{S}}=D .
$$

According to (3), the idealized voltage transmittance of HT can by described by (5) and is shown in Figure 7.

$$
H_{U}^{H T} \cong \frac{U_{L}}{U_{S}}=\frac{n_{a} U_{S} D+n_{b} U_{S}}{U_{S}}=n_{a} D+n_{b} .
$$

Fig. 7. Idealized characteristics of voltage transmittances of presented $\mathrm{HT}$ and $\mathrm{MC}$ as a function of the duty cycle $D$

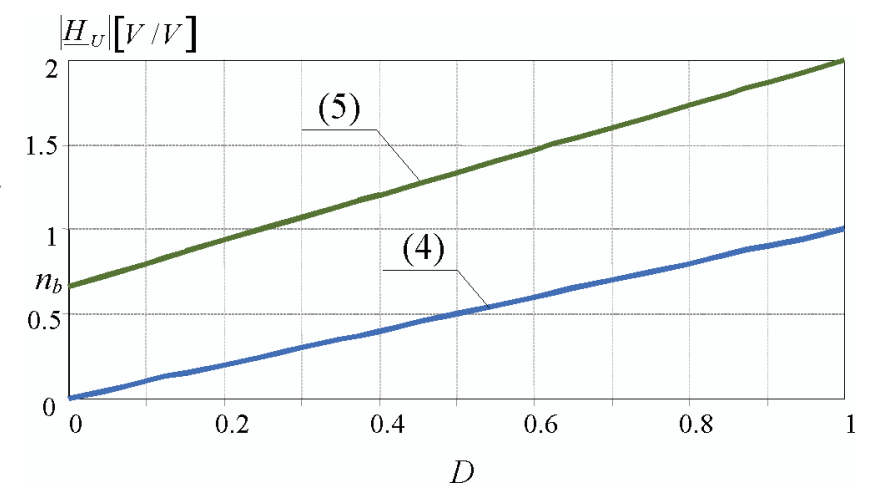

The output voltage of HT $u_{L}$ is dependent on duty cycle $D$ (Fig. 7), and for the considered circuit is controlled from $0.66 u_{S}$ to $2 u_{S}[15,16]$.

Shown in Figures 8 and 9 are exemplary idealized voltage waveforms illustrating the operation of the presented circuit for various values of pulse duty factor $D$, in condition $U_{S}=U_{0}$ with low switching frequency $f_{S}=500 \mathrm{~Hz}$. To give an operational illustration, a resistance load is used. 

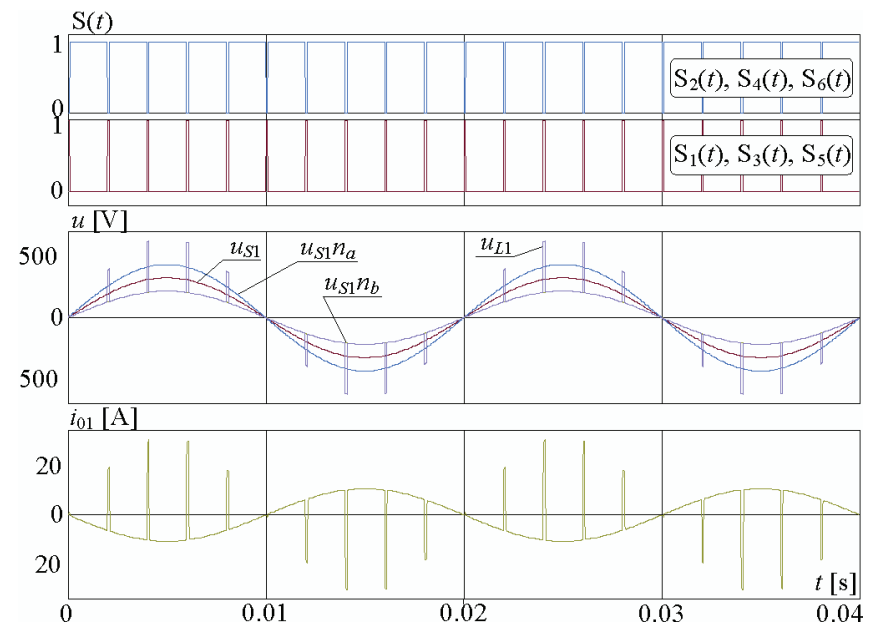

Fig. 8. Idealized voltage and current waveforms for $D=0.1$ and $f_{S}=500 \mathrm{~Hz}$, illustrating operation of analyzed HT

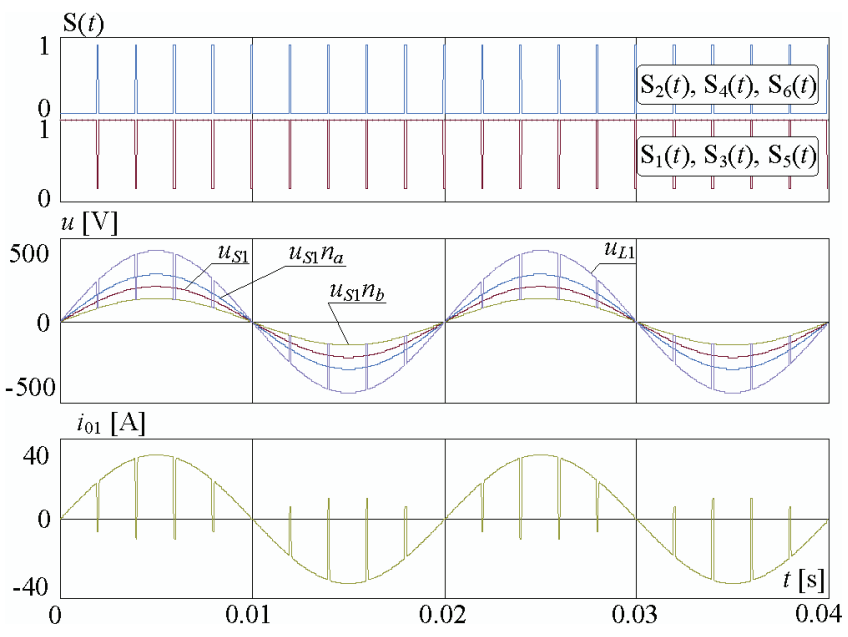

Fig. 9. Idealized voltage and current waveforms for $D=0.9$ and $f_{S}=500 \mathrm{~Hz}$, illustrating operation of analyzed HT

As is visible in Figures 8 and 9, the phase of the load current $i_{0}$ in the HT circuit is dependent on the value of pulse duty factor $D$. If the output voltage of the HT $\left(U_{L}\right)$ is greater than the active load voltage $\left(U_{0}\right)$ (Fig. 9) then the current $i_{0}$ is in phase with the output voltage of the HT. This means that energy is transferred from the source $U_{S}$ to the load (from power system I to power system II). In the case when the output voltage of the HT is less than the active load voltage $\left(U_{S}<U_{0}\right)$ (Fig. 8) then the current $i_{0}$ is in opposite phase in relation to the output voltage of the HT. This means that energy is transferred from the active load to the voltage source $U_{S}$ (from power system II to power system I). 


\section{Theoretical analysis}

Assuming a symmetrical and balanced circuit in the HT and a symmetrical three-phase supply source and active load source, we can show the circuit in Figure 5 as a single phase circuit [15]. Taking into account a substitute scheme of transformer [20] and an averaged circuit model of the matrix chopper [21], the single-phase schematic diagram of the considered HT, after converting all parameters of the TR to a secondary side, is shown in Figure 10.

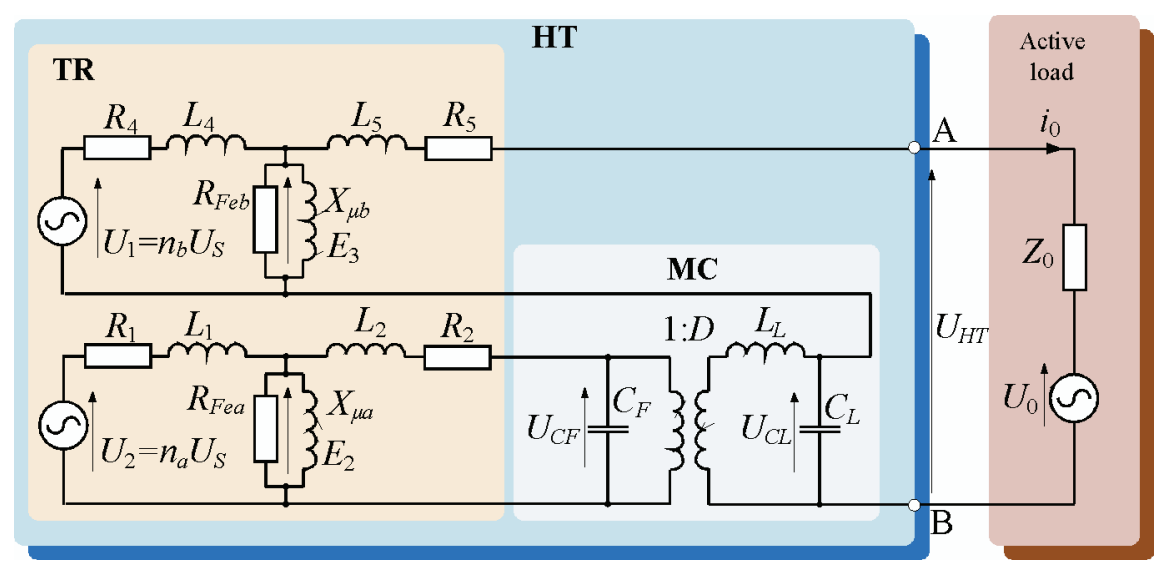

Fig. 10. Single phase model of HT with active load

Table 1. Parameters of substitute circuit of transformer TR conversion to the secondary side of TR

\begin{tabular}{l|c|c|c}
\hline \multicolumn{1}{c|}{ Parameter } & Name & Value & Unit \\
\hline$n_{a}$ & voltage ratio & $4 / 3$ & - \\
\hline$n_{b}$ & voltage ratio & $2 / 3$ & - \\
\hline$R_{1}^{\prime}$ & resistance of primary windings & 1.12 & $\Omega$ \\
\hline$R_{2}$ & resistance of secondary windings $a$ & 0.92 & $\Omega$ \\
\hline$R_{F e a}^{\prime}$ & core losses & 7605 & $\Omega$ \\
\hline$R_{4}^{\prime}$ & resistance of primary windings & 0.28 & $\Omega$ \\
\hline$R_{5}$ & resistance of secondary windings $b$ & 0.163 & $\Omega$ \\
\hline$R_{F e b}^{\prime}$ & core losses & 1901 & $\Omega$ \\
\hline$X_{L 1}^{\prime}$ & leakage reactance & 0.48 & $\Omega$ \\
\hline$X_{L 2}$ & leakage reactance & 0.28 & $\Omega$ \\
\hline$X_{\mu a}^{\prime}$ & magnetizing reactance & 6112 & $\Omega$ \\
\hline$X_{L 4}^{\prime}$ & leakage reactance & 0.036 & $\Omega$ \\
\hline$X_{L 5}$ & leakage reactance & 0.081 & $\Omega$ \\
\hline$X_{\mu b}^{\prime}$ & magnetizing reactance & 1528 & $\Omega$ \\
\hline$U_{S}$ & supply voltage & $230 / 400$ & $\mathrm{~V}$ \\
\hline$U_{1}$ & secondary voltage & $n_{b} U_{S}$ & $\mathrm{~V}$ \\
\hline$U_{2}$ & secondary voltage & $n_{a} U_{S}$ & $\mathrm{~V}$ \\
\hline$S$ & apparent power & 10 & $\mathrm{kVA}$ \\
\hline
\end{tabular}


The parameters of the transformer TR after conversion to the secondary side are collated in Table 1.

On the basis of Thevenin's method, and according to Figure 10, we can very simply obtain the simplify substitute circuit of the analyzed HT with substitute source (Fig. 11).

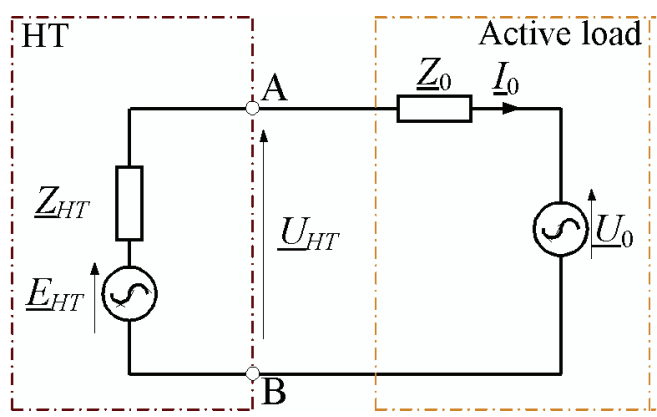

Fig. 11. Simplified equivalent circuit of considered HT with active load

The equivalent source and equivalent impedance of the analysed HT from Figure 11 in complex form are defined as (6) and (7).

$$
\begin{gathered}
\underline{Z}_{H T}=\frac{(106.6-j 244.8)+(0.44-j 317.3) D^{2}}{(-132.75-j 111.84)+D^{2}}, \\
\underline{E}_{H T}=(0.99+j 0.00016) U_{1}-\frac{(49.5+j 133.3) U_{2}}{(-48.47-j 133.15)+D^{2}},
\end{gathered}
$$

where $U_{1}$ and $U_{2}$ are voltages being converted to the secondary side of the transformer TR (Fig. 10, Table 1).

The static characteristics of (6) and (7) and the phase of magnitude of $\underline{E}_{H T}$ as a function of duty cycle $D$ are shown in Figures 12 and 13 .

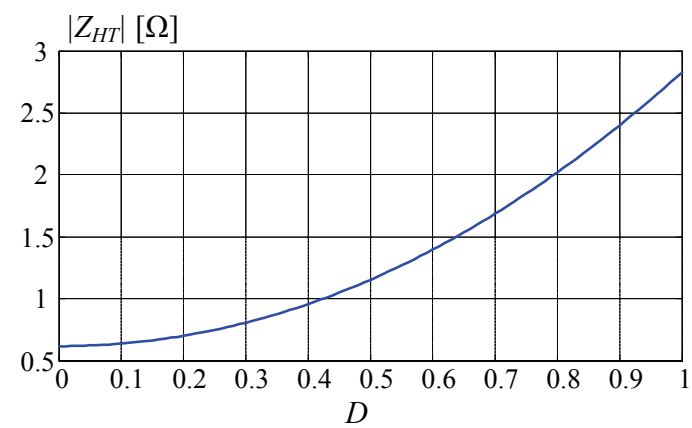

Fig. 12. The magnitude of impedance of HT as a function of $D$

As is visible in Figure 12 the magnitude of the impedance of the HT is dependent on duty cycle $D$ and is changeable in the range 0.6-2.75 $\Omega$. Assuming a supply RMS line voltage of $3 \times 230 \mathrm{~V}$, the range of change of output voltage is from $153 \mathrm{~V}\left(H_{U(D=0)}=2 / 3\right)-460 \mathrm{~V}$ $\left(H_{U(D=1)}=2\right)$ (in accordance with the voltage transmittance of the HT (5) and Fig. 7). 
Fig. 13. The magnitude of the output voltage of HT as a function of $D$

Fig. 14. The phase of output voltage as a function of $D$
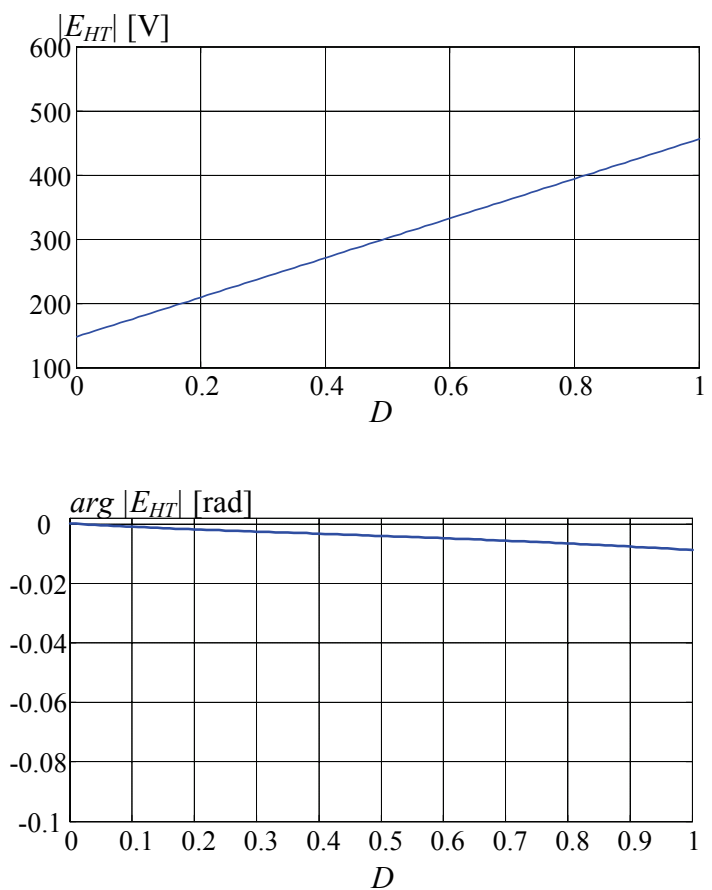

In Figure 13 we can see the static characteristics of the substitute source $\left|E_{H T}\right|$ as a function of duty cycle $D$. Phase shifting $E_{H T}$ voltage (Fig. 14) is caused by passive elements of input and output filters in MC topology and by reactance elements of TR (Fig. 10).

\section{Simulation and experimental tests results}

\section{A) Simulation results}

The parameters of the simulation circuit of the analysed HT with active load are collated in Table 2. The presented simulation results were obtained from the dedicated simulation program PSim. In the simulation model was used idealized passive components and ideal switches. Therefore, the simulation model was operated without dead time.

As is visible in Figs. 15 and 16, the output voltage of the HT $\left(U_{L}\right)$ is dependent on duty cycle $D$. In the case when the output voltage $U_{L}$ is less than the active load voltage $U_{0}\left(U_{L}<U_{0}\right)$ the current $i_{01}$ in the HT circuit is in the opposite phase in relation to the source voltage $u_{\mathrm{S} 1}$. For this reason the instantaneous power $p_{L}$ has negative value (Fig. 15). This means that energy is transferred from source voltage $U_{0}$. If $U_{L}>U_{0}$ (Fig. 16), then instantaneous power $p_{L}$ is positive. This means that energy is transferred from source voltage $U_{S}$.

In the case when source voltage $U_{L}$ is equal to load voltage $U_{S}$ (Fig. 17) the current $I_{0} \approx 0$ and the averaged value of power $P \approx 0$. This means that energy is not transferred in these conditions. 
Table 2. Parameters of simulation circuit

\begin{tabular}{l|c|c|c}
\hline \multicolumn{1}{c|}{ Parameter } & Name & Value & Unit \\
\hline$n_{a}$ & voltage ratio & $4 / 3$ & - \\
\hline$n_{b}$ & voltage ratio & $2 / 3$ & - \\
\hline$U_{S}$ & source voltage & $230 / 400$ & $\mathrm{~V}$ \\
\hline$f$ & supplying frequency & 50 & $\mathrm{~Hz}$ \\
\hline$L_{F 1}=L_{F 2}=L_{F 3}$ & input filter inductance & 1 & $\mathrm{mH}$ \\
\hline$C_{F 1}=C_{F 1}=C_{F 3}$ & input filter capacitance & 10 & $\mu \mathrm{F}$ \\
\hline$L_{L 1}=L_{L 2}=L_{L 3}$ & output filter inductance & 1 & $\mathrm{mH}$ \\
\hline$C_{L 1}=C_{L 2}=C_{L 3}$ & output filter capacitance & 10 & $\mu \mathrm{F}$ \\
\hline$\left|Z_{01}\right|=\left|Z_{02}\right|=\left|Z_{03}\right|$ & load impedance & 10 & $\Omega$ \\
\hline$U_{0}$ & load source voltage & $230 / 400$ & $\mathrm{~V}$ \\
\hline$f_{S}$ & switching frequency & 5 & $\mathrm{kHz}$ \\
\hline$S$ & apparent power & 10 & $\mathrm{kVA}$ \\
\hline
\end{tabular}
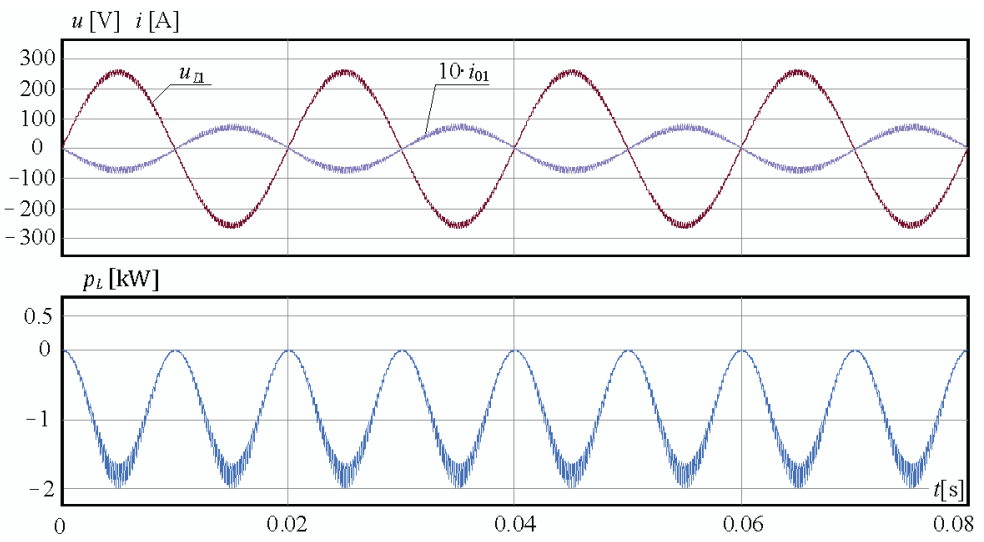

Fig. 15. Simulation waveforms of voltage, current and power for duty cycle $D=0.1$
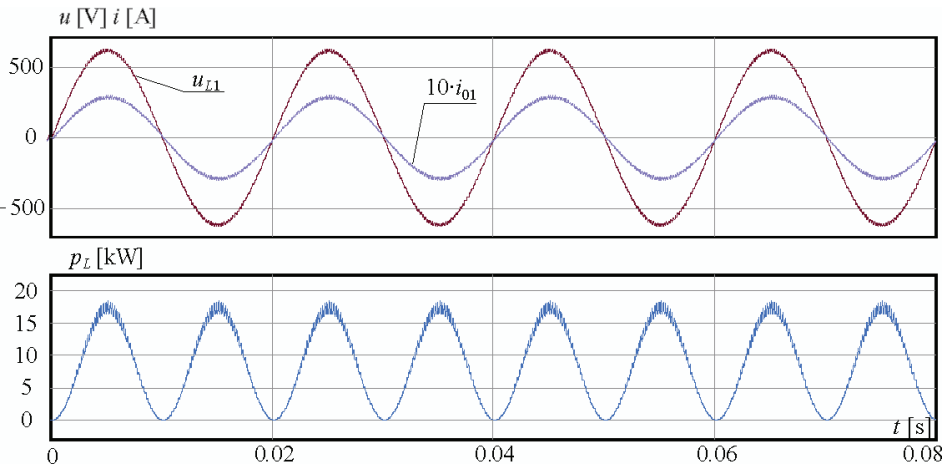

Fig. 16. Simulation waveforms of voltage, current and power for duty cycle $D=0.9$ 

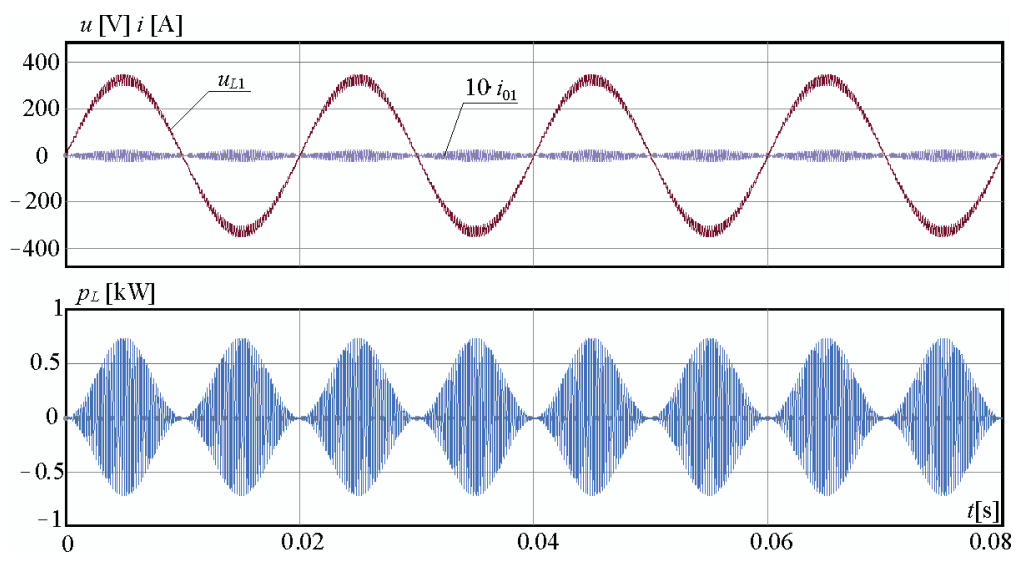

Fig. 17. Simulation waveforms of voltages, currents and instantaneous power for $D=0.25$

\section{B) Experimental results}

A three-phase, 1-kVA prototype has been built and tested in an open-loop control condition. The parameters of the experimental model are shown in Table 3 .

Table 3. Parameters of experimental circuit

\begin{tabular}{l|c|c|c}
\hline \multicolumn{1}{c|}{ Parameter } & Name & Value & Unit \\
\hline$n_{a}$ & voltage ratio & $4 / 3$ & - \\
\hline$n_{b}$ & voltage ratio & $2 / 3$ & - \\
\hline$U_{S}$ & source voltage (rms) & $3 \times 50$ & $\mathrm{~V}$ \\
\hline$f$ & supplying frequency & 50 & $\mathrm{~Hz}$ \\
\hline$L_{F 1}=L_{F 2}=L_{F 3}$ & input filter inductance & 1 & $\mathrm{mH}$ \\
\hline$C_{F 1}=C_{F 1}=C_{F 3}$ & input filter capacitance & 10 & $\mu \mathrm{F}$ \\
\hline$L_{L 1}=L_{L 2}=L_{L 3}$ & output filter inductance & 1 & $\mathrm{mH}$ \\
\hline$C_{L 1}=C_{L 2}=C_{L 3}$ & output filter capacitance & 10 & $\mu \mathrm{F}$ \\
\hline$\left|Z_{01}\right|=\left|Z_{02}\right|=\left|Z_{03}\right|$ & load impedance & 30 & $\Omega$ \\
\hline$U_{0}$ & load source voltage & $3 \times 50$ & $\mathrm{~V}$ \\
\hline$f_{S}$ & switching frequency & 5 & $\mathrm{kHz}$ \\
\hline IGBT & transistors & IRG4PHUD & - \\
\hline $\mathrm{S}$ & apparent power & 10 & $\mathrm{kVA}$ \\
\hline
\end{tabular}

The matrix chopper is controlled via a PWM control strategy. The switching frequency is set to $5 \mathrm{kHz}$, and the "dead time" for commutation is set at $0.7 \mu \mathrm{s}$. The bidirectional switches are implemented with two IRG4PHUD IGBTs connected in emitter-to-emitter configuration. For reasons of safety the AC input rated voltage was $50 \mathrm{~V}_{\mathrm{RMS}}$. The output voltages of considered HT are depend on duty cycle $D$ and can be adjusted flexible from a value smaller than source voltages (Fig. 18a) to about two times greater than source voltages (Fig. 18b). 
a)

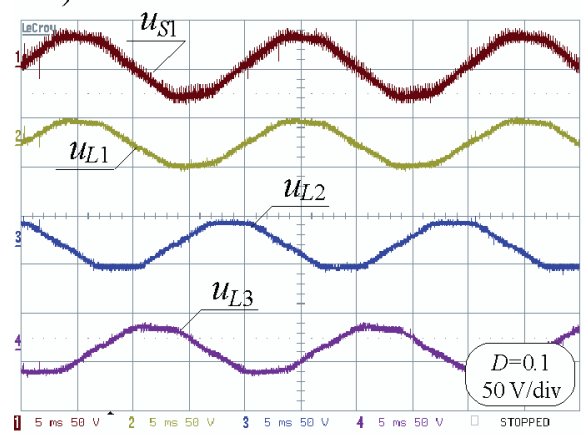

b)

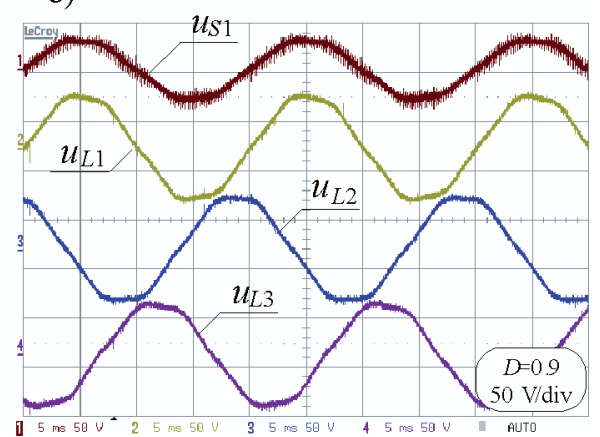

Fig. 18. Experimental line voltage waveforms of HT, for various value of duty cycle: a) $D=0.1$, b) $D=0.9$

The voltages, currents and instantaneous power waveforms for various values of duty cycle $D$ and for $U_{S}=U_{0}$ are shown in Figures 19-21.

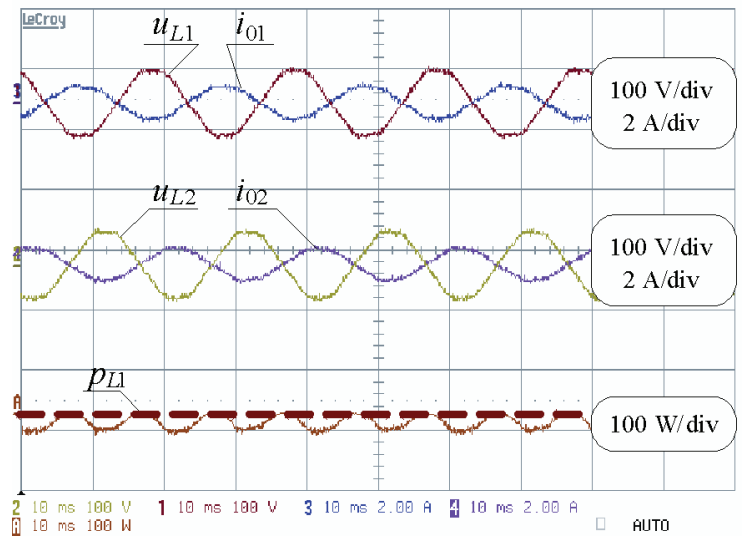

Fig. 19. Experimental waveforms of voltages, currents and power for duty cycle $D=0.1$

As is visible in Figs 19-21, the instantaneous power can be either positive (Fig. 21) or negative (Fig. 19) in value. If the averaged value of instantaneous power $p$ (active power) has a positive value then energy is transfered from source voltage $U_{S}$ to load voltage $U_{L}$, and oposite when $p$ has a negative value. The acquired experimental results validate the theoretical and simulation analysis.

\section{Conclusions}

In this paper a three phase hybrid transformer using a matrix chopper with unsynchronized active load has been presented. The circuit and operation have been described, and the main characteristics and waveforms have been shown. 


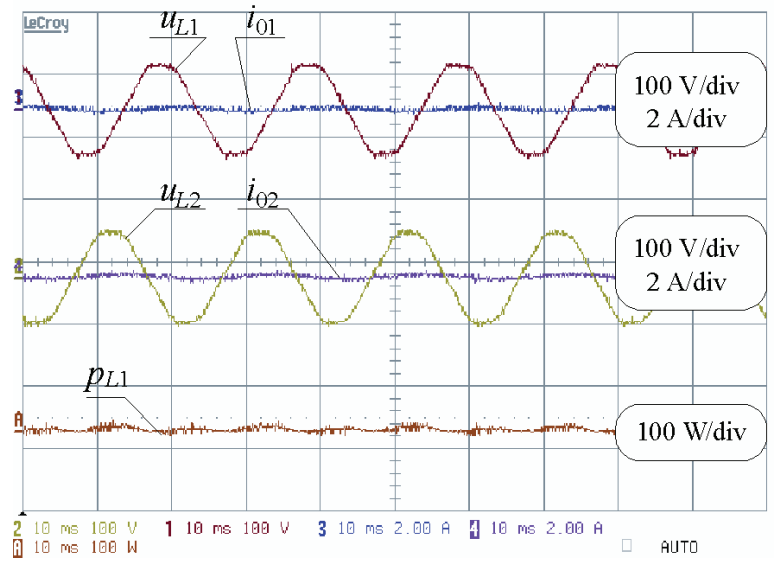

Fig. 20. Experimental waveforms of voltages, currents and power for duty cycle $D=0.25$

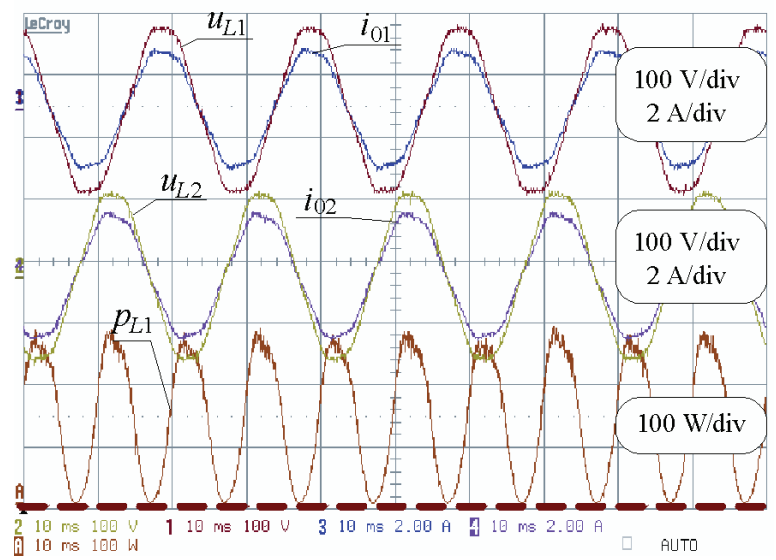

Fig. 21. Experimental waveforms of voltages, currents and power for duty cycle $D=0.9$

This prototype was operated using a control strategy based on the PWM modulation of the IGBTs. The described solution allows the possibility for bidirectional energy flow in a power system with active load. The acquired experimental results validate theoretical and simulation analysis. Theoretical analysis, in compare to simulation and experimental tests, was based on averaged circuit model (stationary model). The non-stationary simulation model was constructed with bidirectional ideal switches and idealized passive elements. The theoretical, simulation and experimental test results are consistent. Future research will be focused on the analysis of the HT with an active load and closed-control loop and possibility to control energy transfer in low voltage power systems under conditions of source and load voltage fluctuations. 


\section{Acknowledgement}

The project has been funded by the National Science Centre granted on the basis of decision number DEC-2011/03/B/ST8/06214

\section{References}

[1] Standard EN 50160, Voltage Characteristics of Public Distribution Systems.

[2] Conrad, L., Little, K., Grigg, C., Predicting and preventing problems associated with remote fault - clearing voltage dips. IEEE Trans. on Ind. Applications 27(1): 167-172 (1991).

[3] Milanowić J., Hiskansen I., Effect of load dynamics on power system damping. IEEE Trans. on Power System 10(2): 1022-1028 (1995).

[4] Djokic Z., Desment J., Vanalme G. et al., Sensitivity of personal computer to voltage sags and short interruptions IEEE Trans. on Power Delivery 20(1): 375-383 (2005).

[5] Bollen M., Zang L., Analysis of voltage tolerance of ac adjustable - speed drives for three phase balanced and unbalanced sags. IEEE Trans. on Ind. Applications 36(3): 904-910 (2000).

[6] Falce A., Matas G., Da Silva Y., Voltage sag analysis and solution for an industrial plant with embedded induction motors. Proc. Ind. Applications Conference 4: 2573-2578 (2004).

[7] Honrubia-Escribano A., Gómez-Lázaro E., Molina-García A., Fuentes J.A., Influence of voltage dips on industrial equipment: Analysis and assessment. Elsevier, Electrical Power and Energy Systems 41: 87-95 (2012).

[8] Strzelecki R., Benysek G., Jarnut M., Energy balancing system for end-user customers. Electrical Review 84: 17-19 (2008)

[9] Strzelecki R., Benysek G., Jarnut, M., Power Quality Conditioners with Minimum Number of Current Sensors Requirement, Electrical Review 84: 295-298 (2008).

[10] Jang D., Choe G., Step-up/down ac voltage regulator using transformer with tap changer and PWM ac chopper. IEEE Trans. on Ind. Electronics 45(6): 905-911 (1998).

[11] Fedyczak Z., Frąckowiak L., Jankowski M., Kempski A., Single - phase serial ac voltage controller based on bipolar PWM ac matrix - reactance chopper. Proc. 11th European Conference on Power Electronics and Applications, Dresden (2005).

[12] Aeloiza E., Enjeti P., Moran L., Pite I., Next generation distribution transformer: to address power quality for critical loads. Proc. PESC'03, IEEE 3: 1266-1271 (2003).

[13] Kaniewski J. Single phase hybrid transformer using matrix converter (in Polish). Electrotechnical News, pp: 46-48 (2006).

[14] Fedyczak Z., Kaniewski J., Single phase hybrid transformer using bipolar matrix - reactance chopper. (In Polish), Electrical Review, pp: 80-85 (2006).

[15] Fedyczak Z., Kaniewski J., Modeling and analysis of hybrid transformer using matrix converter. Proc. CPE Conf., Gdańsk (2007).

[16] Kaniewski J., Analysis and study of properties of the hybrid transformers. Ph.D. dissertation, University of Zielona Góra Press. (In Polish) (2011).

[17] Kaniewski, J., Practical application of series active compensators. [In:] Benysek G., Pasko M. (Ed.), Power theories for improved power quality. Springer, pp.: 187-210 (2012)

[18] Kaniewski J., Modeling and analysis of three-phase hybrid transformer using buck-boost MRC. Proc. 7th international conference-workshop Compatibility and Power Electronics - CPE 2011, Tallinn, Estonia, 202-207 (2011).

[19] Kaniewski, J., Fedyczak, Z., Benysek, G., AC voltage sag/swell compensator based on three-phase hybrid transformer with buck-boost matrix-reactance chopper. IEEE Trans. on Ind. Electronics, manuscript accepted for publication, September 19, (2013).

[20] Jezierski, E., Transformers - Theoretical Fundamentals. (In Polish), WNT Warszawa (1965).

[21] Fedyczak Z., PWM AC voltage transforming circuits. (In Polish) University of Zielona Góra Press (2003).

[22] Kaniewski, J., Fedyczak, Z., Klytta et al., Implementation of a three-phase hybrid transformer using a matrix chopper. Proc. 13th European Conference on Power Electronics and Applications, Barcelona, Hiszpania (2009). 